\title{
Psychology’s Borrowings from Medical Methodology: Analog Comparisons
}

\author{
Pascal Henri Keller, Marion Haza \\ Department of Psychology, EA4050, CAPS, Poitiers University, Poitiers, France \\ Email: marion.haza@gmail.com
}

Received March 19 $9^{\text {th }}$, 2013; revised April 23 ${ }^{\text {rd }}$ 2013; accepted May 21 $1^{\text {st }}, 2013$

\begin{abstract}
Copyright (c) 2013 Pascal Henri Keller, Marion Haza. This is an open access article distributed under the Creative Commons Attribution License, which permits unrestricted use, distribution, and reproduction in any medium, provided the original work is properly cited.
\end{abstract}

\begin{abstract}
Medical advances force practitioners to work in an increasingly standardized manner with their patients. Quantitative health psychology attempts to follow a similar path by adopting, for the same patients, methods that are equally systematized. In this article, the origin of such an attempt will first be positioned historically. The clinical method will then be used to establish that, while patients tend to accept the constraints imposed by the medical technique, they usually resist those resulting from quantitative psychology. Based on clinical observations, we will present several ways in which such resistance may manifest itself. This article aims to further the understanding of qualitative health in psychology.
\end{abstract}

Keywords: Clinical Approach; Analogous Methods; Critical Health Psychology; Medical Research

\section{Introduction}

Historically, psychology was "born” out of medicine (Keller, P.H., EHPS Symposium, 2010, Cluj Napoca, Romania). The founder of scientific psychology in France, Théodule Ribot, demanded from the first psychologists that they first have a degree in medicine. Today, while the experimental method remains entirely suitable and efficient when it comes to studying biological matter in medicine, it seems an inefficient way of examining "the raison d'être of a phenomenon" (Lambrichs, 1993). This is because such a question raises the problem of "sense", which the social sciences, and psychology in particular, explore in their research. However, psychology is still influenced by its origins, and all the more so when its research takes place in contact with medicine (Keller-Senon, 2007). Indeed, "health psychology" considered for a long time that its "biopsycho-social" model (Bruchon-Schweitzer, 2001) enabled it to present figures as reliable as those obtained, in their domain, by its medical partners. The concept of "stress", both objectifiable and quantifiable, represented the peak of such an approach, integrating psychological models with the medical ones. The research conducted since the 2000s by "critical health psychology” (Santiago-Delefosse \& Chamberlain, 2008) moves away from the purely quantitative approach of health psychology, with "qualitative" data and in-depth analysis, taking into account and incorporating the discourse of the ill person.

Despite the attacks it sometimes faces (Lee, 2006), critical health psychology pursues its researches, considering itself as "an approach more than a theory" (Hook, 2004). For instance, Hook reckons that one of the basic concerns of critical psychology is aimed at "self-evident assumptions". He points out that these assumptions, carried on by health psychology, and related to reality, human nature and knowledge, are only generated by "a certain group, according to a way of doing, and with an eye to some interests” (Hook, 2004: p. 16).
Most of the time, health psychology is confined to copying medical practices in an attempt to find its rightful place in the form of a "biopsychosocial" (BPS) model. On the other hand, the perspective maintained by Santiago-Delefosse proposed to go beyond a notion of the ill human being as a juxtaposition of BPS variables. It refers to a theoretical approach that is clearly psychological and no longer anchored in a biomedical definition: the Embodied-Socio-Psychological (ESP) perspective (Santiago-Delefosse, 2011).

Other psychological approaches, such as the narrative approach, that neglects strictly quantitative aspects, begin to study closely oral exchanges between practitioners and patients, and even achieve to raise the interest of the medical world to a psychology different from health psychology (Davidsen \& Reventlow, 2011)

The purpose of this article is not so much to highlight the impasse reached by "non-critical" health psychology as to shed light on some of its epistemological aspects. Even if the discipline is sometimes lucid as to the limits of its main "bio-psycho-social" model, it is interesting to analyze the logic of reasoning that led it to take the path it did. The logic of its reasoning is partly based on what psychology (Secrétan, 1992; Ricoeur, 1975) and literature call "analogy", We will therefore refer to clinical psychology work on analogical mental functioning in medicine (Ducousso-Lacaze \& Keller, 1995; Keller \& Ducousso-Lacaze, 2004), as well as to some other work on analogy (Laflaquière \& Ducousso-Lacaze, 2003).

\section{Analogous Method}

A subject commonly studied in its own right in philosophy, linguistics and cognitive psychology, reasoning has not been studied so much in clinical situations. It is nevertheless a mode of thinking that comes easily to speakers when interviewed.

Analogy is a linguistic process that, in a general way, is in- 
volved in communication between humans. Analogy articulates, through language, "an effective, legitimate and thought-out resemblance between dissimilar terms” (Secrétan, 1984). This definition contains the two terms that form the basis of the interest from a psychic dynamics point of view: resemblance and dissimilarity. The second of these has often been ignored. In principle and according to this definition, analogical reasoning therefore consists in bringing together (purely through thought) notions, data or facts that, in the first place, are completely unrelated. In terms of reasoning structure, analogy can be expressed in the following form: $A / B=C / D$ (" $A$ is to $B$ what $C$ is to $\mathrm{D}$ ”). If somebody formulates an analogy to an interlocutor, he or she does so mainly so as to be better understood by the other. The structure makes it possible to bring together two domains that, without it, would have no reason whatsoever to be associated with each other. This is the way in which everyone uses analogy, without always measuring its real impact on the thinking of other people. When resorting to it, nobody thinks of stating that his/her reasoning is based on an analogy. In fact, when a speaker uses analogical reasoning, he or she has an intention to enhance his/her interlocutor's understanding of a point and uses a particular linguistic means of achieving his/ her goals i.e. putting together two universes that had until then been separate.

Generally speaking, and particularly in medicine, using analogy presupposes a certain lucidity as to the point and the limits of one's intention, as well as the pertinence of the wording used.

For psychologists in medicine, it is particularly appropriate to take an interest in analogy. Often, in order to have their erudite discourse on the psycho-corporal identity of their patients accepted, medical practitioners use analogy, without necessarily always understanding the effect of this reasoning on the patient, an effect that can sometimes be intrusive.

This is what we can see in the following case: a doctor speaks to an adolescent who has just been diagnosed with diabetes. After announcing this diagnosis, the doctor states that diabetes is "a lifelong illness," and that the treatment consists in injecting oneself everyday with insulin, adding that "the daily injections are no more serious than brushing your teeth." The analogy proposed by the doctor therefore simply consists in relating the dental hygiene of the adolescent to the daily care he needs to take of his diabetes. The young patient does not say anything at the time but, some years later, he will confide to a psychologist that, "in all his life, he had never heard more violent words" (Keller, 2007). The intended effect-to make the young man understand that his diabetes treatment has to become something familiar-is based on the analogy between brushing one's teeth and injecting oneself with insulin (the brushing of the teeth 1) is to general hygiene 2) what insulin injection 3) is to diabetes 4)). But what is considered as "familiar" for the doctor is not the same for the young patient. In this case, the use of analogy provokes the opposite of the intended effect: after this announcement and, the young patient will neglect his treatment for several years, sometimes risking coma. What is more, social discourse does not escape such improper use of analogy. It is therefore not unusual to find formulations such as: "Unemployment, a cancer on society". The structure of the analogy in this statement can be expressed as follows: "Unemployment 1) is to society 2) what cancer 3) is to the body 4)”. In other words: there is the same connection between unemployment and society as there is between the human body and cancer. The essayist Susan Sontag (in Illness as a metaphor) considers that analogies between cancer and social disasters (war, delinquency, drugs, unemployment, etc.) actually create additional suffering for the patients afflicted by this illness. She considers that the use of this analogy shows ignorance regarding cancer and a lack of respect towards the patients (Sontag, 2005).

To sum up, analogy can be considered as a "relevant method", efficient and useful if it enables us to deepen our reflection, destructive on the contrary if it inhibits it. To avoid slipups, let us describe how it is used in three steps, necessary for appropriate use: first, the speaker must announce the analogy, that is, prepare the interlocutor and conditioning him/her to think on the basis of the analogical reasoning proposed. He/she understands that the analogy is going to put together two universes that, until then, were completely unrelated for him/her. The aim is that the patient should then implement this reasoning his/her own way, and not to impose it on him/her. The second step enables us to validate the reasons for bringing the two elements together by "work on similarity” (Keller \& DucoussoLacaze, 2004). The shared reflection at this stage is about identifying the points of similarity between the two domains put together by analogy. Lastly, the third and most important step addresses the distance that separates the two domains put together by the analogical formulation. Named "work on dissimilarity” (Keller \& Ducousso-Lacaze, 2004), this stage consists in re-establishing a distance between the elements that have just been brought together. This step is crucial, particularly in medicine, since it limits the risks of misunderstandings between the interlocutors. It provides a reminder that, after being brought together, the two universes then separate, with, on one hand, medical knowledge based on science, and on the other hand lay knowledge, based on the history and subjectivity of the patient.

\section{Methodological Inputs Borrowed to Medicine}

This presentation of analogy might be enough to consider that, for medicine, the qualitative approach in psychology is more appropriate than the quantitative one. By giving priority to the patient's words, critical health psychology highlights his/ her history and subjective life, as well as his/her participation in the evolution of his/her physical suffering, in the context of an organic illness. In contrast, by giving priority to figures based on pre-established questionnaires or scales, health psychology has little reason to be interested in analogy. However, use of analogical reasoning here is aimed less at comparing these two schools of psychological thought than at thinking about the situation of research in medicine when it concerns the psychological life of patients.

As early as 2006, M. Santiago proposed to bring an end to the "turbulence" provoked, in psychological research, by the confrontation between the "positive-neo-positive" paradigm and the "subjective-constructive" paradigm (Santiago-Delefosse, 2006). Analogical reasoning might help us better understand where the opposition stands between these two conceptions of psychology, both of which are at work in the medical field.

We propose an analogy, from the point of view of the research approach, between medicine on one side and health psychology on the other: "In clinical research, the body is to medicine what the mind is to psychology.” However simplistic it may be, this formulation does at least define the object of research in these two disciplines. As mentioned before, ana- 
logical reasoning may be misleading if used without been mentioned (Keller, 2007), but introducing it at the beginning of the demonstration enables the reader (or the listener) to clearly identify its interest, without ever losing sight of its limits. In a clinical research situation, all practitioners-researchers are confronted with rules. Physicians and psychologists have long been mixed up, as is the case in the Declaration of Helsinki, which, since 1964, has set out the ethical principles applicable to medical research involving human subjects. In France, in 1988, the "Huriet-Sérusclat" law defined the conditions for the protection of people involved in biomedical research. We nevertheless had to wait almost 20 more years for psychological research to be explicitly mentioned in these texts, and even then only in relation to the information given to the patient: "The objective of a psychological research project, as well as its methodology and duration, may be explained in a short preliminary brief as long as the research is being carried out on healthy volunteers and does not pose any foreseeable serious risk. Complete information on the research is given when it is over to the persons who participated in it" (Public Health Code. Biomedical research, article L1122-1, 2006). In other words, until this date, from a legal point of view, the psychologistsresearchers in this domain could put psychology on the same level as medicine, which was mixed up with it. This is also what the definitions established by psychologists working in contact with medicine show, as evidenced by this excerpt from a psychological work. "(Health) psychology can be defined as the study of health and illness, focusing on the importance and the role of the interdependence of psychological, social and biological factors in the maintaining of health or the onset and evolution of illnesses;" and, later on, "in the case of cancer, existing studies highlight several psychological characteristics linked to the emergence and evolution of these pathologies" (Fisher \& Tarquino, 2006). In the reflection on analogy between medicine and psychology, the step on "work on similarity" therefore implies that, generally speaking, some elements would be common to the two disciplines: pathologies (infectious diseases, cancer, heart disorders, etc.), objectives (illness prevention, health study, therapeutic action, etc.), notions (diagnosis, aetiology, risk factors, epidemic, prevention, etc.), methods ("objective" data sampling, "objective" statisticcal analysis, presentation of "objective” scientific results, etc.), and, last but not least, interlocutors (patients, patients' families, medical staff, etc.).

Over the last ten years or so, authorities have realized that, in research, psychology belongs to a non-medical sector: "social sciences.” They increasingly tend to call this field "behavioural sciences” (Caverni, 1998). In this context, psychological research carried out in medicine has progressively been divided up into quantitative research on one hand and qualitative research on the other. In other words, while biomedicine retains and sometimes reinforces-its experimental procedures, psychology is loosening its methodological system. There are now two options. The first, we know, is a system based on the experimental method borrowed from medicine (mainly based on the manipulation of variables), with the collection of data, mainly figures. The second calls upon qualitative methods, of a "dialogical, dialectical, phenomenological, interactional, hermeneutic” type (Santiago-Delofosse, 2006). For now, let us note that in biomedical research, the dissimilarities between medicine and psychology are mainly due to this partition of psychology into two distinct sets. A first point of dissimilarity between medicine and psychology is therefore established: medicine remains a full-fledged discipline, united around EBM ("Evidence Based Medicine”), whereas psychology is in broad outline split in two (qualitative psychology and quantitative psychology). De facto, we are witnessing a pushing away of works coming from the "qualitative" school of psychology, where psychological works have to stay within the medical research framework defined by the Declaration of Helsinki. In this framework, only the research protocols satisfying the methodological requirements imposed by biomedicine can be examined: verifiable procedures, validated tools, figures, repeatable results. (Cousson-Gélie, 2011).

It is on that very point that a second point of dissimilarity can be established. Indeed, the quantitative approach to psychology bases its scientific claims on its similarity to the medical template that is still used as a reference. However, a close review of its research tools and results in fact reveals the difference between these two disciplines and sheds light on the characteristics of their dissimilarity.

\section{Dissimilarities between Quantitative Psychology and Medicine}

As if they were becoming aware of these dissimilarities, but without clearly stating it, some European countries (France, 2003; Belgium, 2006; Switzerland, 2009; etc.), have begun to propose regulations specific to social sciences research in general, and psychology in particular. In 2006, the WHO even organized an international conference in Denmark, based on the acknowledgement of an "epidemic of psychosocial distress and mental ill health in Europe”.

As we saw earlier, psychology and medicine sometimes, within this legislative framework of international research (Declaration of Helsinki, Hurriet Lax), use a common vocabulary. If the research protocols submitted to research ethics committees show this community of words, paying particular attention to the meaning of these words enables us to reveal the dissimilarities between the two disciplines. It can be easily spotted, either when medicine has recourse to the terms usually used by psychology, or when psychology uses words from medicine. Furthermore, most medical protocols report a problem facing specialists in a specific body pathology, the researchers' aim being to resolve this problem. A hypothesis is then proposed, as well as the method to be used to confirm it. The judgment criteria; that will be used to determine if the research fulfills its objectives or not are then listed. Lastly, the risks are described, making it possible to consider the cost/benefit ratio of the research for the patient. In ophthalmology for example, in order to improve the treatment of cataracts, glaucoma or myopia, the researchers have to stick to the procedure and report, at each step, all the data necessary to validate it. The result is the improvement of the patient's sight, which is accurately measured. These strict and precise protocols, unlike those involving psychology, more often than not yield unambiguous results. Another dissimilarity concerns placebos (Geirso \& Keller, 2009). Medical methodology uses this subterfuge (administering a product that is inert from a pharmacological point of view in order to compare its effects to those of the product being trialled) in order to neutralize the psychological impact of a prescription. There is probably no better way to show how medicine differs, in research, from psychology. We can illustrate this with the example of a research project, "Relationship between adiposity, 
emotional status and eating behaviour in obese women: the role of inflammation", that tries to scientifically merge psychology and medicine. Conducted among around a hundred women, before or after they underwent surgery to have a gastric band fitted, the project aimed to establish a link between, on one hand, their body and biological state (overweight, inflammation, etc.), and, on the other hand, some aspects of their psychological state (neuroticism, anxiety, depression, etc.). In this method, the tools used to collect the biological markers (blood test and fat samples) and the tools used to measure the "psychological" indicators (questionnaires, scales, automatized tests) are presented side by side. This presentation therefore assumes and equivalence between all the collected data, biological or psychological. This research gives priority to the resemblance between medical and psychological procedures. However, we can still note at least two characteristic dissimilarities: firstly, the biological data have a material existence and can be directly observed and measured (in our example: interleukin, adipokin, etc.); secondly, the psychological data are intangible (answers to questions) and are indirectly observed or deduced (here, "social support," “quality of life,” “depression,” etc.). In addition, the biological data are manually collected by the medical staff with no intervention whatsoever from the patient (syringe, dosing devices, etc.); on the contrary, psychological data are obtained through tools designed in a specific culture, and their content necessarily depends on the will of the patient to submit to them.

\section{Conclusion}

In biology, a "chimaera” is a hybrid organism, composed of cells of two distinct genetic origins. By analogy, can we say that health psychology is a chimeric discipline? The fact remains that still today, medicine seems to keep its distances from such psychology. Several reasons can explain such mistrust. On one hand, health psychology uses tools that sometimes reveal the contradiction between the practitioners and the patients' judgment on the interest and the beneficial effects of a medical treatment (Macquart-Moulin, Viens, Bouscary et al., 1997). On the other hand, if some medical acts entail a complex psychological dimension, where the relational aspect is determining, it is hard to implement the involvement of psychologists alongside practitioners, whatever the reason. In that respect, the reasoning used in both disciplines often applies to objects of different nature: biologic for some, psychological for the others. And yet, in most cases, the distinction between the reality of the body and the imagination of the psyche is essential, especially to the patient (Terry, Gareth, Braun, \& Virginia, 2013). Nevertheless, sometimes the interested professionals don't take into account this difference, however fundamental in the relationship with the patient. Finally, among the source of lack of understanding or misunderstanding between medicine and psychology specialists, we can highlight that practitioner's training, especially in Europe, only includes a few hours of psychology. This gap maintains a problematic distance between the two disciplines, a distance that health psychology persistently tries to reduce. If psychology has to play a part alongside medicine, it would rather be achieved by a diversification at the theoretic-clinical level than by trying to mimic the unique principle of evidence-based medicine. This is how critical health psychology currently multiplies its efforts, for example by proposing to diversify research methods instead of unifying them
(Dures et al., 2011). By distancing themselves from the dogma of cognitive psychology, some authors also question the idea that conscious and rational information would enable an evolution of representations in medicine. These authors call on other areas of relevance in order to improve the situation of people who request medical expertise (Santiago- Delefosse, 2012).

Regarding the hesitation it raises among its medical partners, psychology would therefore be well-advised to ponder on at least two levels. On one hand, quantitative health psychology could give up on mimicking medicine, enabling for the elaboration of specific tools, more centered on the patient's feelings. And, on the other hand, by turning for instance to the study of the "placebo relationship" from the hypothesis of the unconscious, critical health psychology could renew the interest in the speech of all partners involved in care.

Today, the Declaration of Helsinki on biomedical research is evolving and now puts in the notion of "research involving human subjects"”. As a consequence of such an evolution of the regulations on medical research, psychology research projects will have to be approved by a Committee for the Protection of the People (CPP) before being set up ${ }^{2}$. Isn't this the opportunity for psychology to have the plurality of its researches acknowledged and to prove its relevance in the health field?

\section{Acknowledgements}

The auteurs thanks Pr Marie Santiago-Delefosse, University of Lausanne (Ch), Institute of Psychology, CeRPSa and the organizers of the 25th Conference of the European Health Psychology Society.

\section{REFERENCES}

Amouretti, M. (2004). L’approche de la qualité de vie en médecine: De la recherche clinique à la pratique quotidienne. Quality of life in medicine: From clinical research to practice, Gastroentérologie Clinique et Biologique, 28, 9-10.

Association Mieux Prescrire (2009). Effets des anticancéreux sur la durée de survie: Souvent mal évalués, Revue Prescrire, 29, 218-221.

Bowling, A. (2001). Measuring disease (2nd ed.). Buckingham: Open University Press, 23-68.

Bruchon-Schweitzer, M. (2002). Psychologie de la Santé. Modèles, concepts, méthodes. Paris: Dunod.

Capuron, L. et al. (2011). Relationship between adiposity, emotional status and eating behaviour in obese women: Role of inflammation. Psychological Medicine, 41, 1517-1528.

Caverni, J.-P. (1998). Pour un code de conduite des chercheurs dans les sciences du comportement humain. L'année Psychologique, 98, 83100.

Ducousso-Lacaze, A., \& Keller, P.-H. (1995). Maladie, métaphore et analogie: Une approche clinique et théorique. Revue Internationale de Psychopathologie, 20, 615-640.

Fischer, G., \& Tarquinio, C. (2006). Les concepts fondamentaux de la psychologie de la santé. Paris: Dunod.

Gelber, S. et al. (1998). Using the Q-TWIST method for treatment comparisons in clinical trials. In M. J. Staquet (Ed.), Quality of life assessment in clinical trials. Methods and practices (pp. 281-296). Oxford: Oxford University Press.

Keller, P.-H., \& Ducousso-Lacaze, A. (2004). Clinique de l'inattendu: Apport de l'analogie. Bulletin de Psychologie, 57, 457-464.

Keller, P.-H. (2007). Le maniement de l'analogie dans le raisonnement freudien. Topique, 98, 245-264.

\footnotetext{
${ }^{1}$ http://www.wma.net/fr/40news/20archives/2013/2013_08/

${ }^{2}$ In France, promulgation of the Jardé Law, n 2012-300 of March 5th, 2012, related to researches on individuals.
} 


\section{P. H. KELLER, M. HAZA}

Keller, P.-H., \& Senon, J.-L. (2007). Psychologie en médecine, encyclopédie médico-chirurgicale. Psychiatrie, 1-6

Laflaquière, A., \& Ducousso-Lacaze, A. (2004). Les destins de l'analogie. Bulletin de Psychologie, 487-502.

Lee, C. (2006). Critical health psychology: Who benefits? Journal of Health Psychology, 11, 355-359. doi:10.1177/1359105306063303

Launois, R. et al. (1994). Construction et validation d'un indicateur spécifique de qualité de vie: Le cas de l'insuffisance veineuse chronique des membres inférieurs. Journal d'Economie Médicale.

Macquart-Moulin, G., Vien, S. P., Bouscary, M. L. et al. (1997). Discordance between physicians' estimations and breast cancer patients' self-assessment of side-effects of chemotherapy: An issue for quality of care. British Journal of Cancer, 76, 1640-1645.

doi:10.1038/bjc.1997.610

Moret, L. et al. (1993). Evaluer la qualité de vie: Construction d'une échelle. Revue d'Epidémiologie et de Santé Publique, 41, 65-71.
Santiago Delefosse, M. (2011). An embodied-socio-psychological perspective in health psychology? Social and Personality Psychology Compass, 5, 220-230. doi:10.1111/j.1751-9004.2011.00345.x

Santiago-Delefosse, M. (2012). Deconstructing the notion of "belief" in psychology: Commentary on "beyond belief". Journal of Health Psychology, 17, 974-976. doi:10.1177/1359105311435947

Sontag, S. (2005). La maladie comme métaphore. Paris: Seuil. Staquet, M. J. et al. (1998) Quality of life assessment in clinical trials. Methods and practices. Oxford: Oxford University Press, 281-296.

Terry, G., \& Braun, V. (2013). We have friends, for example, and he will not get a vasectomy. Health Psychology, 32, 100-109. doi:10.1037/a0029081

www.wma.net/fr/30publications/10policies/b3/17c_fr.pdf http://www.euro.who.int/PubRequest 